\title{
Angiotensin ( $1-7)$ prevent heart dysfunction and left ventricular remodeling caused by renal dysfunction in 5/6 nephrectomy mice
}

\author{
Yiwen Li, Jianyong Wu, Qiang He, Zhangfei Shou, Ping Zhang, Wenhan Pen, Yilin Zhu and Jianghua Chen
}

The renin-angiotensin system (RAS) plays a critical role in chronic renal failure associated with heart failure. In the past few years, angiotensin (Ang) (1-7) have been reported to counteract the effects of angiotensin II (Ang II) and were even considered as a new therapeutical target in RAS. The purposes of this study were to examine whether the Ang (1-7) improves the heart function and remodeling of the left ventricle (LV) in mice with 5/6 nephrectomy (NC). We used a 5/6 nephrectomy to induce significant renal dysfunction in wildtype mice (WT). Twelve weeks after NC, WT showed high blood pressure, significant leftventricular dilation and dysfunction, which were accompanied by cardiomyocyte hypertrophy, diffuse interstitial fibrosis and oxidative damage of cardiomyocytes. Exogenous Ang (1-7) injection improved the heart function and remodeling of LV in mice with $5 / 6 \mathrm{NC}$ accompanied by a reduction in cardiac interstitial fibrosis, inflammatory cytokine expression and oxidative damage levels of cardiomyocytes, decrease in the profibrotic signaling molecule transforming growth factor (TGF)- $\beta$ and increase in the collagen degradation signaling molecule matrix metalloproteinase (MMP)-2, -9. However, these beneficial effects did not occur in hydralazine-treated mice. These findings suggest that (1) Exogenous Ang (1-7) injection improve the heart function and remodeling of $L V$ in mice with 5/6 NC. (2) These beneficial effects are independent of its anti-blood pressure effect. Hypertension Research (2009) 32, 369-374; doi:10.1038/hr.2009.25; published online 27 March 2009

Keywords: angiotensin (1-7); experimental models; heart failure; renal failure

\section{INTRODUCTION}

In patients with renal failure cardiovascular complications are an important clinical problem, and cardiovascular complications are the leading cause of death in patients with end-stage renal disease (ESRD), accounting for $40 \%$ of the deaths in these patients. ${ }^{1}$ Ischemic heart disease, heart failure and cardiomyopathy are the most frequent causes of cardiac death in ESRD. Cross-sectional studies have shown that left ventricular hypertrophy $(\mathrm{LVH})$ is the most frequent cardiac alteration in ESRD and is an independent risk factor for survival. ${ }^{2}$ In ESRD, the LVH usually accompanies hypertrophy of cardiomyocytes, diffuse interstitial fibrosis and a decrease in myocardial capillary supply. ${ }^{3}$ Cardiac cytokines that are stimulated by Ang II, such as interleukin (IL) $1 \beta$ and transforming growth factor (TGF) $\beta 1$, are involved in the development of cardiac fibrosis and in cardiac failure. ${ }^{4,5}$ The LVH and myocardial fibrosis may also occur because of non-hemodynamic factors such as parathyroid hormone, endothelin, aldosterone and an increased sympathetic nerve discharge. ${ }^{6}$ Increasing evidences have proved that Ang II is an independent risk factor for cardiovascular disease. It acts directly on the myocardium to cause ventricular hypertrophy. ${ }^{7}$ Drugs that interfere with the renin-angiotensin system, such as the angiotensin-converting enzyme inhibitor (ACEI) and Ang
II-receptor blocker (ARB), are widely accepted for the treatment of chronic renal failure and heart failure.

Recent studies have found that the angiotensin-converting enzyme (ACE) homolog ACE2 efficiently hydrolyzes Ang II to form Ang (1-7), a group of peptides that exert actions opposite to those of Ang II. ${ }^{8}$ Low doses of Ang (1-7) improve cardiac output and antagonize Ang II-induced vasoconstriction. ${ }^{9}$ The biological activity of Angs (1-7) is tissue specific and dose-dependent. ${ }^{10}$ These findings point toward a possible protective role of Ang (1-7) in abating the Ang II-induced actions. It has been reported that Ang (1-7) may inhibit oxidative stress, stimulate plasminogen activator inhibitor 1 production and platelet aggregation, and act as an anti-inflammatory agent. ${ }^{11}$ It has also been found that Ang (1-7) have a cardioprotective effect in the rat. Ang (1-7) decrease the incidence and duration of ischemia/reperfusion arrhythmias $^{12}$ and improve post-ischemic function in the isolated rat heart. ${ }^{13}$ Angs (1-7) are also effective in preventing heart failure after myocardial ischemia, induced by left coronary artery ligation. ${ }^{14}$ Therefore, we hypothesize that chronic infusion of Ang (1-7) should prevent cardiac remodeling induced by chronic renal failure. The purpose of this study was to examine whether the Ang (1-7) would improve heart function and remodeling of LV in mice with 5/6 NC. 


\section{METHODS}

\section{Animal experiments}

This study was approved by our Institutional Animal Research Committee. Male C57BL/ 6J 12 weeks old mice were used in the study. All mice were housed under controlled humidity, temperature and 12-h light-dark cycles. All mice were allowed free access to standard laboratory-mouse chow and tap water. The 5/6 kidney-ablation animal model was developed by removal of both poles of the right kidney and a week later, by the removal of the left kidney. The mice were divided into three groups (10 mice pergroup). The control group received saline treatment. Ang (1-7) (Sigma-Aldrich, St Louis, MO, USA) and hydralazine groups were given, angs $(1-7)$ at a dose of $300 \mu \mathrm{g} \mathrm{kg}^{-1} \mathrm{day}^{-1}$ and hydralazine at a dose of $15 \mathrm{mg} \mathrm{kg}^{-1} \mathrm{day}^{-1}$, in a mini-osmotic pump, embedded s.c.; sham-operated mice received no treatment or Ang (1-7). Blood pressure was measured before and every 2 weeks after treatment by the tail-cuff method. All mice were killed at 12 weeks after the operation.

\section{Blood sample}

Before and after the experiment, the blood samples were collected bfrom the tail vein and carotid artery, and were used for the measurement of serum creatinine and blood urea nitrogen (BUN).

\section{Physiology studies}

Echocardiograms were recorded using an echocardiographic system (Aloka, Tokyo, Japan), equipped with a 7.5-MHz imaging transducer, at 12 weeks after operation. After echocardiography, the right-carotid artery was cannulated with a micro-manometer-tipped catheter (SPR 407, Millar Instrument, Houston, TX, USA) and was advanced into the aorta and then into the left ventricle for recording the pressures and $\pm \mathrm{d} p / \mathrm{d} t$.

\section{Histological analysis}

After measurement, all mice were killed and the hearts were removed. The hearts were cut into two transverse slices at the middle of the ventricle. The apical specimens were frozen quickly under liquid nitrogen. The basal specimens were fixed with $10 \%$ buffered formalin and embedded in paraffin. Four-micrometerthick sections were stained with hematoxylin-eosin or Sirius red. Quantitative assessments, including cardiomyocyte sizeand the fibrotic area were performed using a multipurpose color image processor, LUZEX F (Nireco, Tokyo, Japan).

\section{Western blotting}

Protein $(100 \mu \mathrm{g})$ extracted from the heart tissues was subjected to $10 \%$ polyacrylmide gel electrophoresis and then transferred onto PVDF membranes. The membranes were then probed using a primary antibody against transforming growth factor (TGF- $\beta$, Promega, Madison, WI, USA), matrix metalloproteinase-2 (MMP-2; Daiichi Fine Chemical Co, Takaoka, Toyama, Japan), MMP-9 and Mas (both from Santa Cruz Biotechnology, Santa Cruz, CA, USA). The blot was visualized by means of chemiluminescence (ECL, Amersham, UK) and the signals were quantified by densitometry. $\alpha$-Tubulin (analyzed using antibody from Sigma-Aldrich) was used as the loading control.

\section{Immunohistochemistry}

The $4 \mu \mathrm{m}$-thick deparaffinized sections or $8 \mu \mathrm{m}$-thick cryosections from the apical half of the ventricle were incubated with a primary antibody against 8-hydroxy-20-deoxyguanosine (8-OHdG; Japan Institute of the Control of Aging, Shizuoka, Japan). The ABC kit (Dako, Ely, UK) was used for the immunostaining of the deparaffinized section with 3,3 diaminobenzidine (DAB) as the chromogen. The sections were observed under a light microscope.

\section{ELISA}

Cardiac IL-1 $\beta$, IL-6 and tumor necrosis factor (TNF)- $\alpha$ protein contents were quantified using ELISA kits (Quantikine M, R\&D Systems, Minneapolis, MN, USA) according to the supplier's instruction.

\section{Statistical analysis}

Values are shown as mean \pm s.e.m. The significance of differences in the finding was evaluated using $t$-tests. Values of $P<0.05$ were considered to be significant.

\section{RESULTS}

\section{Changes in systolic blood pressure}

At baseline, all groups presented similar systolic blood pressure (SBP) levels. At 12 weeks after operation, the control group presented a significant increase in the SBP level, Ang (1-7) and hydralazine-treated mice showed a significant low-level SBP andthere was no difference between the sham mice and sham+Ang (1-7) mice (Table 1).

\section{Changes in serum creatinine}

At 12 weeks after operation, the serum creatinine levels of the three groups were increased significantly compared with the sham group. But the level of serum creatinine in Ang (1-7)-treated mice was significantly lower than that in untreated WT mice and hydralazinetreated mice (Table 1).

\section{Cardiac function at 12 weeks after 5/6 nephrectomy}

According to the echocardiography and cardiac catheterization at 12 weeks post-operation, the mice showed decreased cardiac function (Table 2): LV fraction shortening (\%FS), lower LV developed pressure (LVDP), and reduced maximal and minimal $\mathrm{d} p / \mathrm{d} t$ compared with sham-operated mice. It should be noted that these values were significantly better in the Ang (1-7)-treated mice, but not in the hydralazine-treated mice.

Histopathology of the heart at 12 weeks after 5/6 nephrectomy We found that in the untreated WT mice, cardiomyocytes had significantly increased in size at 12 weeks after $5 / 6 \mathrm{NC}$, and that this effect was significantly attenuated in the Ang (1-7)-treated mice, but not in the hydralazine-treated mice (Figure 1). In addition, substantial myocardial interstitial fibrosis (assessed by Sirius-red staining) devel-

Table 1 Blood pressure and renal function in mice 12 weeks after 5/6 nephrectomy

5/6 nephrectomy

\begin{tabular}{llccc} 
& Sham $(\mathrm{n}=15)$ & Sham+Ang (1-7) $(\mathrm{n}=15)$ & $5 / 6$ NC $(\mathrm{n}=15)$ & 5/6 NC+hydralazine $(\mathrm{n}=15)$ \\
\hline CRE & $0.31 \pm 0.05$ & $0.30 \pm 0.08$ & $0.853 \pm 0.053^{*}$ & $0.76 \pm 0.18^{*, \#}$ \\
BUN & $28.2 \pm 3.7$ & $29.1 \pm 3.5$ & $93.5 \pm 8.0^{*}$ & $90 \pm 27^{*, \#}$ \\
SBP & $81.2 \pm 5.6$ & $78.3 \pm 5.3$ & $97.1 \pm 9.8^{*}$ & $77 \pm 7.9^{\#}$ \\
\hline
\end{tabular}

Abbreviations: Ang, angiotensin; BUN, blood urea nitrogen (mg per $100 \mathrm{ml}$ ); CRE, serum creatinine (mg per $100 \mathrm{ml})$; NC, nephrectomy; SBP, systolic blood pressure.

$* P<0.05$ vs. sham-operated mice.

${ }^{*} P<0.05$ vs. Sham-operate
$\# P<0.05$ vs. $5 / 6 \mathrm{NC}$ mice.

$P<0.05$ vs. $5 / 6 \mathrm{NC}+$ hydralazine mice.

Data are expressed as mean \pm s.d. 
Table 2 Left ventricular geometry and function assessed 12 weeks after 5/6 nephrectomy in mice

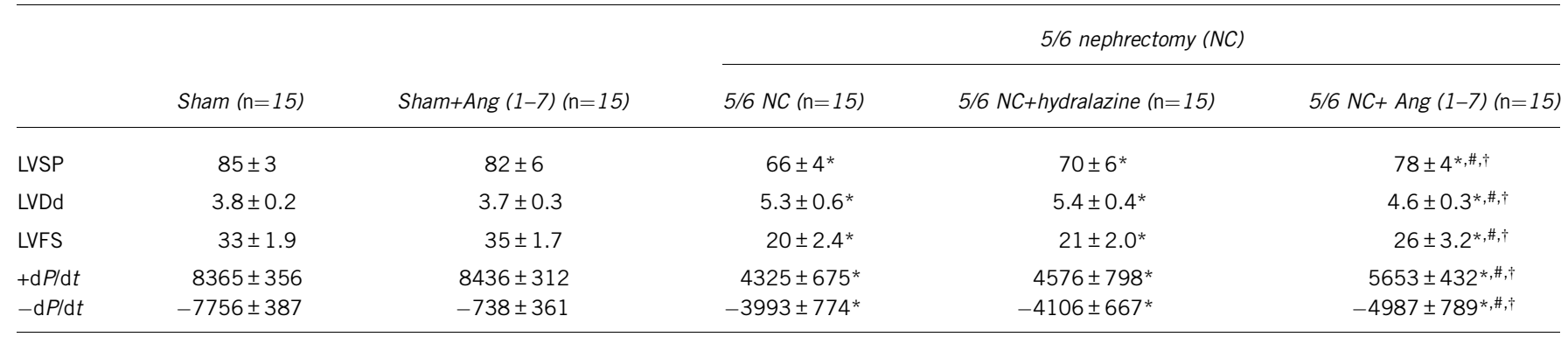

Abbreviations: LVSP, left ventricular systolic pressure (mm Hg); LVDd, LV end-diastolic diameter (mm); LVFS, LV fractional shortening $(\%) ;+\mathrm{d} P / \mathrm{d} t, \mathrm{maximal} \mathrm{d} P / \mathrm{d} t\left(\mathrm{~mm} \mathrm{Hg} \mathrm{s}^{-1}\right) ; \mathrm{d} P / \mathrm{d} t, \mathrm{minimal} \mathrm{d} P / \mathrm{d} t$ $\left(\mathrm{mm} \mathrm{Hg} \mathrm{s}^{-1}\right)$.

${ }^{*} P<0.05$ vs. sham-operated mice.

${ }^{\#} P<0.05$ vs. $5 / 6 \mathrm{NC}$ mice.

$\dagger P<0.05$ vs. $5 / 6$ NC+hydralazine mice.

Data are expressed as mean \pm s.d.

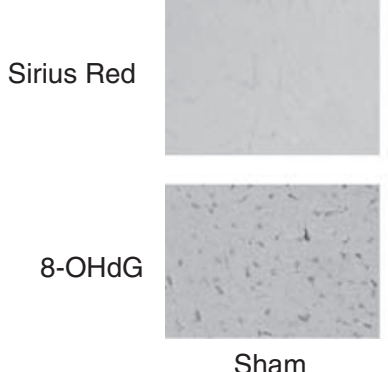

Sham

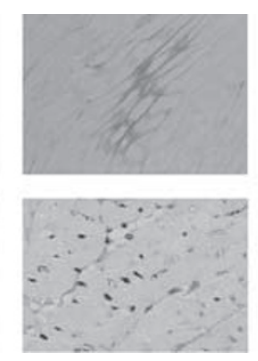

$5 / 6 \mathrm{NC}$
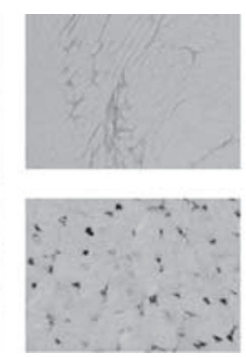

$5 / 6 \mathrm{NC}+$ Hydralazine
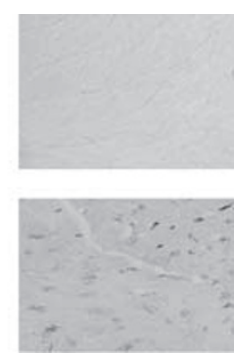

5/6 NC+ Ang (1-7) cardiomyocytes size $(\mu \mathrm{m})$

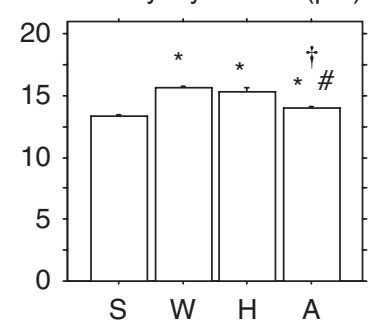

Sirius Red positive Area (\%)

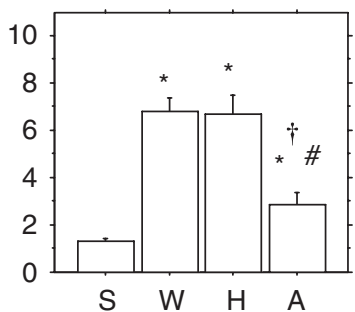

8-OHdG-positive myocytes (\%)

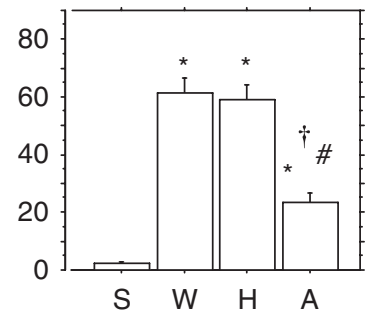

Figure 1 Morphometric analysis of cardiomyocyte size, myocardial fibrosis and oxidative damage in the heart assessed 12 weeks after the $5 / 6$ nephrectomy (NC) in sham-operated mice (S, $n=10)$, untreated WT mice (W, $n=10)$, hydralazine-treated mice $(H, 10)$ and angiotensin (Ang) (1-7)-treated mice (A, $n=10) .{ }^{*} P<0.05$ vs. sham-operated mice. ${ }^{\#} P<0.05$ vs. untreated WT mice. ${ }^{\dagger} P<0.05$ vs. hydralazine-treated mice. 8-OhdG, 8-hydroxy-2'-deoxyguanosine.

oped in all groups after the NC, although the area of fibrosis was significantly smaller in the Ang (1-7)-treated mice (Figure 1). The DNA base-modified product 8 -OHdG is one of the most commonly used markers for the evaluation of oxidative DNA damage. ${ }^{8}$ Such oxidative damage was significantly attenuated in the Ang (1-7)-treated mice, but not in the hydralazine-treated mice (Figure 1).

\section{Myocardial expression of TGF- $\beta$, MMP-2, -9 and Mas}

We examined the expression of TGF- $\beta$ MMP-2, -9 and Mas in the heart tissues. As TGF- $\beta$ overexpression is the main reason for myocardial fibrosis, ${ }^{9}$ the effects of MMP-2 and -9 were controlled by TGF- $\beta$. Western blot analysis revealed that TGF- $\beta$ was downregulated and the MMP-2 and -9 were significantly overexpressed in Ang (1-7)-treated mice compared with untreated WT mice and hydralazine-treated mice (Figure 2).

Western blot analysis revealed that the Ang (1-7)-receptor Mas was up-regulated in the 5/6 NC mice compared with the sham mice.
Ang (1-7) treatment significantly increased the expression of Mas in myocardium (Figure 2).

\section{Cardiac IL-1 $\beta$, IL-6 and TNF- $\alpha$ protein content}

The expression of inflammatory cytokines IL-1 $\beta$, IL- 6 and TNF- $\alpha$ was significantly increased in untreated WT mice. Inflammatory-cytokine expression was less increased in Ang (1-7)-treated mice than in untreated WT mice and hydralazine-treated mice (Figure 3).

\section{DISCUSSION}

In this study, we examined the effect of Ang (1-7) administration on the established cases of chronic heart failure in a 5/6 NC mouse model. We observed a significant increase of SBP in the 5/6 NC, accompanied by cardiac dysfunction as shown by the echocardiogram, hemodynamic examination, myocyte hypertrophy, myocardial interstitial fibrosis, myocytes oxidative DNA damage and by the significantly higher levels of IL-1 $\beta$, IL- 6 and TNF- $\alpha$ in the myocardial tissues. 

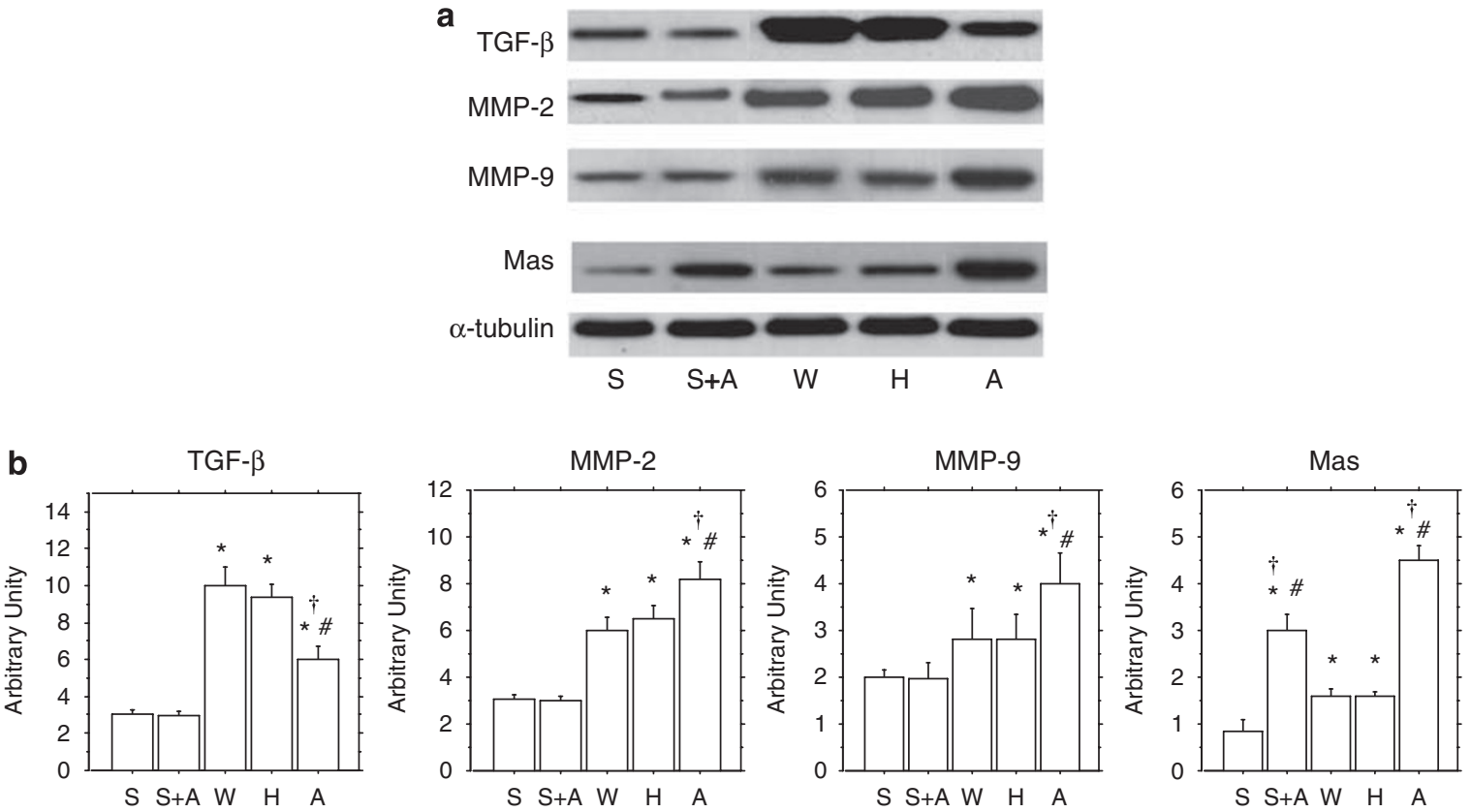

Figure 2 (a) Western blot analysis of myocardial expression of transforming growth factor (TGF)- $\beta$, matrix metalloproteinase (MMP)-2, MMP-9 and Mas assessed 12 weeks after 5/6 nephrectomy in sham-operated (S, $n=5)$, Ang-(1-7)-treated sham-operated ( $+A$, $n=5)$, untreated wild-type (W, $n=5$ ), hydralazine-treated wild-type $(H, n=5)$, and Ang-(1-7)-treated wild-type $(A, n=5)$ mice. (b) Densitometric analysis of the relative myocardial expression levels of (A) TGF- $\beta$, (B) MMP-2, (C) MMP-9 and (D) Mas assessed 12 weeks after 5/6 nephrectomy in sham-operated (S, $n=5$ ), angiotensin (Ang) (1-7) treated sham-operated $(S+A, n=5)$, untreated wild-type (W, $n=5)$, hydralazine-treated wild-type $(H, n=5)$ and Ang (1-7)-treated wild-type (A, $n=5)$ mice. ${ }^{*} P<0.05$ vs. sham-operated mice. ${ }^{\#} P<0.05$ vs. untreated wild-type mice. ${ }^{\dagger} P<0.05$ vs. hydralazine-treated mice.
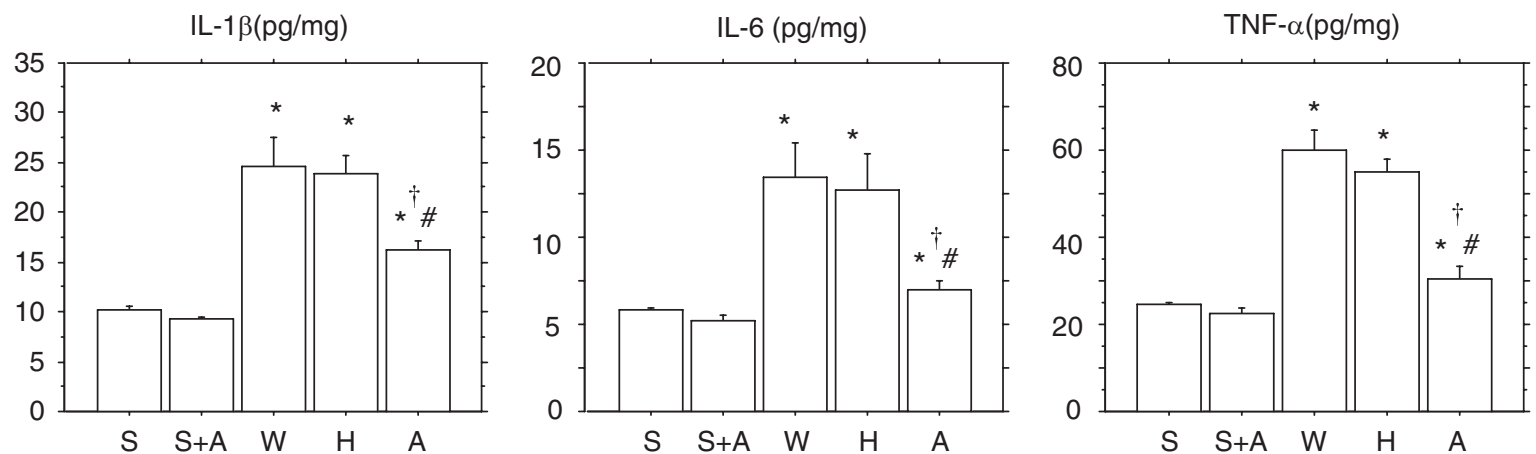

Figure 3 Enzyme-linked immunosorbent assay (ELISA)-based analysis of interleukin (IL)-1 $\beta$, IL- 6 and tumor necrosis factor (TNF)- $\alpha$ in myocardium assessed 12 weeks after 5/6 nephrectomy in sham-operated ( $S, n=10)$, Ang-(1-7)-treated sham mice ( $+A, n=10)$, untreated WT mice (W, $n=10)$, hydralazinetreated mice $(H, n=10)$ and Ang-(1-7)-treated mice $(A, n=10)$. ${ }^{*} P<0.05$ vs. sham-operated mice. ${ }^{\#} P<0.05$ vs. untreated control mice. ${ }^{\dagger} P<0.05$ vs. hydralazine-treated mice.

Ang (1-7)-treated mice showed significantly lowered-SBP and attenuated cardiac dysfunction, interstitial fibrosis, reduced myocyte oxidative DNA damage and reduction in the elevated levels of IL$1 \beta$, IL- 6 and TNF- $\alpha$ expression in the failing myocardium. On the other hand, NC led to upregulation of myocardial expression of TGF$\beta$, MM-2, MMP-9 and Ang (1-7) receptor Mas. Ang (1-7) treatment inhibited the overexpression of TGF- $\beta$ and further increased the expression of MMP-2, MMP-9 and Mas.

A very important pathological character in ESRD is LVH accompanied by diffuse myocardial interstitial fibrosis. ${ }^{5}$ A large body of evidence has accumulated over the past two decades to support the notion that angiotensin II, through its AT1 receptor, mediates myocardial interstitial fibrosis and cardiomyocyte hypertrophy, ${ }^{9,10}$ but it does not directly stimulate cardiomyocytes growth and fibrosis in the adult myocardium, but does so indirectly by inducing the expression of TGF- $\beta$, which then acts locally through the auto/paracrine mechanism. ${ }^{11,12}$ TGF- $\beta$ is a locally generated cytokine that has been implicated as a major contributor to tissue fibrosis in various organ systems. ${ }^{13}$ Antagonists of the RAS, such as ACE inhibitors and angiotensin-receptor blockers, attenuate the fibrotic changes and matrix deposition mediated by TGF- $\beta$. Recently, Peterson ${ }^{14}$ showed that both cardiac hypertrophy and fibrosis in heart failure are characterized by an elevated level of circulating TGF- $\beta$ and Fedulov et al. ${ }^{15}$ showed a strong positive correlation between serum TGF- $\beta$ and cardiac fibrosis. Okada ${ }^{16}$ has also recently shown that gene therapy directed against TGF- $\beta$ attenuates left ventricular remodeling and heart failure, after a myocardial infarction, in a time-dependent manner. 
MMPs are a family of enzymes that catalyze the degradation of the extracellular matrix and are believed to play important roles in heart disease. ${ }^{17,18}$ MMPs play a crucial role in the complex interplay between inflammatory and vascular cells, fibroblasts and cardiomyocytes, which can result in myocardial protection or destruction, depending on the etiology of the cardiac damage. ${ }^{19}$ Theoretically, however, an increase in the myocardial MMP activity likely translates into more collagen degradation, which would ultimately reduce cardiac fibrosis.

Our study found that in Ang (1-7)-treated mice myocardial interstitial fibrosis was significantly reduced, accompanied by a lower expression of TGF- $\beta$ and an overexpression of MMP-2 and MMP-9. These suggest that the effects of Ang (1-7) on cardiac remodeling may be related to the decrease in the pro-fibrotic signaling molecule TGF- $\beta$ and the increase in the collagen-degradation signaling molecule MMP-2, -9. We also observed that Ang (1-7) treatment reduced the elevated levels of IL- $1 \beta$, IL- 6 and TNF- $\alpha$ expression in the failing myocardium. Several studies have shown that in both animals and humans with failing hearts, levels of inflammatory cytokines (e.g., IL-1 $\beta$, IL-6 and TNF- $\alpha$ ) are increased in the plasma ${ }^{20,21}$ and in the circulating leukocytes, ${ }^{22}$ as well as in the myocardium itself. ${ }^{23-25}$ Our observation that the levels of IL-1 $\beta$, IL- 6 and TNF- $\alpha$ were elevated in the failing myocardium of mice, 12 weeks after $5 / 6 \mathrm{NC}$, is consistent with those of earlier findings. It is important to note that the expression of these inflammatory cytokines is reportedly directly related to the degree of heart failure and inversely related to the survival. $^{23,26}$ Moreover, the results from animal studies and some clinical pilot trials have suggested that suppression of inflammatory cytokines may improve the cardiac performance..$^{27,28}$ Recently, Oudit et al. $^{29}$ found that the expression of inflammatory cytokines, IL-1 $\beta$, IL-6 and monocyte chemotactic protein-1 (MCP-1) in the ACE2 null age-dependent cardiomyopathy mice was increased. Their results also showed that the age-dependent cardiomyopathy in ACE2 null mice is related to increased Ang II-mediated oxidative stress and inflammation through the AT1 receptors. Furthermore, the new $\operatorname{Ang}(1-7)$ forming enzyme ACE2 has been reported to be an important regulator of the RAS. This enzyme can produce Ang (1-7) by at least two different pathways: directly from Ang II and indirectly from Ang I. ${ }^{30}$ These results suggest that Angs (1-7) may play a beneficial role in anti-inflammatory function. Although speculative, it is therefore conceivable that a reduction in inflammatory cytokines may be one of the mechanisms involved in the beneficial effect of Ang (1-7) on failing hearts caused by $5 / 6 \mathrm{NC}$.

This study also revealed the anti-oxidant effect of Ang (1-7) on a failing myocardium. Ang (1-7) significantly reduced the number of cardiomyocytes positive for 8-OHdG, a commonly used marker of oxidative DNA damage. ${ }^{31}$ Along with inflammatory cytokines, the overproduction of reactive oxygen species is also thought to be involved in myocardial remodeling. ${ }^{32}$ Apparently, inflammatory cytokines can induce oxidative stress-for example, TNF- $\alpha$ can directly induce the production of mitochondrial reactive oxygen species in the cardiomyocytes, causing damage to the mitochondrial DNA, ${ }^{33}$ -whereas oxidative stress can increase the levels of inflammatory cytokines, leading to the development of a vicious cycle in the failing hearts. ${ }^{34,35}$ In this study, the anti-oxidative effect of Ang (1-7) may be attributed to its anti-inflammation effect. However, Ang (1-7) may directly inhibit the oxidative stress. ${ }^{36}$

We also found that the expression level of Ang (1-7)-receptor Mas was markedly higher in the untreated failing hearts than in the shamoperated hearts, but it was still higher in the Ang (1-7)-treated failing hearts. This phenomenon reflects a ligand-dependent autoinduction of Mas gene expression, similar to the situation that has been reported for hepatocyte growth factor (HGF) and c-Met/HGF receptor. ${ }^{37}$ Recently, Santos et al. ${ }^{38}$ found that genetic deletion of the Mas receptor caused significantly deleterious effects on cardiac function and structure, particularly with regard to myocardial fibrosis, which suggests that Mas is necessary for Ang-(1-7) transduction. However, the exact mechanism through which Ang (1-7) increased the Mas expression has not been elucidated yet. Mas signal activates a variety of intracellular signaling cascades, including the JAK/STAT, Ras/Raf/MAPK and PI3K/Akt pathways. ${ }^{39-42}$ The biological effects of Ang (1-7), such as inhibiting the growth of cardiac myocytes, angiogenesis and antioxidative stress, were already reported in earlier studies related to the activation of these cell signal pathways. ${ }^{39-42}$ The beneficial effects of Ang (1-7) therapy on chronic heart failure caused by chronic renal failure in this study also may be related to the activation of these cell signal pathways.

In summary, our findings suggest that renal-dysfunction-associated heart failure can be attenuated by chronic infusion of Ang (1-7), which inhibits cardiomyocyte hypertrophy and interstitial fibrosis. These effects seem to be related to the reduced expression of inflammatory cytokines and oxidative damage, decrease in the profibrotic signaling molecule TGF- $\beta$ and increase in the collagen-degradation signaling molecule MMP-2, -9. However, determination of the precise mechanism behind all these will require further study.

\section{ACKNOWLEDGEMENTS}

This study was supported by Research Grants QJD0702015, 2008R10024 and Y208031 from the Science and Technology Department of Zhejiang province, China.

1 Foley RN, Parfrey PS, Sarnak M. Cardiovascular disease in chronic renal disease: clinical epidemiology of cardiovascular disease in chronic renal disease. Am J Kidney Dis 1998; 32 (Suppl 3): s112-s119.

2 Silberberg J, Barre PE, Prichard SS, Sniderman AD. Impact of left ventricular hypertrophy on survival in end-stage renal disease. Kidney Int 1989; 36: 286-290.

3 Tyralla K, Amann K. Cardiovascular changes in renal failure. Blood Purif 2002; 20 : $462-465$.

4 Sun Y, Zhang J, Lu L, Bedigian MP, Robinson AD, Weber KT. Tissue angiotensin II in the regulation of inflammatory and fibrogenic components of repair in the rat heart. $J \mathrm{Lab}$ Clin Med 2004; 143: 41-51.

5 Torre-Amione G, Kapadia S, Benedict C, Oral H, Young JB, Mann DL. Proinflammatory cytokine levels in patients with depressed left ventricular ejection fraction: a report from the Studies of Left Ventricular Dysfunction (SOLVD). J Am Coll Cardiol 1996; 27: 1201-1206.

6 London GM. Left ventricular alterations and end-stage renal disease. Nephrol Dial Transplant 2002; 17 (Suppl 1): 29-36.

7 Brunner HR. Experimental and clinical evidence that angiotensin II is an independent risk factor for cardiovascular disease. Am J Cardiol 2001; 87 (8A): 3C-9C.

8 Toyokuni S, Tanaka T, Hattori Y, Nishiyama Y, Yoshida A, Uchida K, Hiai H, Ochi H, Osawa T. Quantitative immunohistochemical determination of 8-hydroxy-2'-deoxyguanosine by a monoclonal antibody N45.1: its application to ferric nitrilotriacetateinduced renal carcinogenesis model. Lab Invest 1997; 76: 365-374.

9 Brunner HR. Experimental and clinical evidence that angiotensin II is an independent risk factor for cardiovascular disease. Am J Cardiol 2001; 87: 3Ce9C.

10 Shibasaki Y, Nishiue T, Masaki H, Matsubara H, Iwasaka T. Angiotensin II type 1 antagonist suppress left ventricular hypertrophy and myocardial fibrosis in patient with end stage renal disease (ESRD) [in Japanese]. Nippon Rinsho 2002; 60: 1992e8.

11 Ferreira AJ, Santos RAS, Almeida AP. Angiotensin-(1-7): cardioprotective effect in myocardial ischemia/reperfusion. Hypertension 2001; 38 (part 2): 665-668.

12 Ferreira AJ, Santos RAS, Almeida AP. Angiotensin-(1-7) improves the post-ischemic function in isolated perfused rat hearts. Braz J Med Biol Res 2002; 35: 1083-1090.

13 Loot AE, Roks AJM, Henning RH, Tio RA, Suurmeijer AJH, Boomsma F, van Gilst WH. Angiotensin-(1-7) attenuates the development of heart failure after myocardial infarction in rats. Circulation 2002; 105: 1548-1550.

14 Peterson MC. Circulating transforming growth factor beta-1: a partial molecular explanation for associations between hypertension, diabetes, obesity, smoking and human disease involving fibrosis. Med Sci Monit 2005; 11: RA229-RA232. 
15 Fedulov AV, Ses TP, Gavrisheva NA, Rybakova MG, Vassilyeva JG, Tkachenko SB, Kallner A, MacMillan JC. Serum TGF-beta 1 and TNF-alpha levels and cardiac fibrosis in experimental chronic renal failure. Immunol Invest 2005; 34: 143-152.

16 Okada H, Takemura G, Kosai K, Li Y, Takahashi T, Esaki M, Yuge K, Miyata S, Maruyama R, Mikami A, Minatoguchi S, Fujiwara T, Fujiwara H. Postinfarction gene therapy against transforming growth factor-beta signal modulates infarct tissue dynamics and attenuates left ventricular remodeling and heart failure. Circulation 2005; 111: 2430-2437.

17 Spinale FG. Matrix metalloproteinases: regulation and dysregulation in the failing heart. Circ Res 2002; 90: 520e30.

18 Heymans S, Schroen B, Vermeersch P, Milting H, Gao F, Kassner A, Gillijns H, Herijgers $P$, Flameng W, Carmeliet P, Van de Werf F, Pinto YM, Janssens S. Increased cardiac expression of tissue inhibitor of metalloproteinase- 1 and tissue inhibitor of metalloproteinase-2 is related to cardiac fibrosis and dysfunction in the chronic pressureoverloaded human heart. Circulation 2005; 112: 1136e44.

19 Panek AN, Bader M. Matrix reloaded: the matrix metalloproteinase paradox. Hypertension 2006; 47: 640-641.

20 Testa M, Yeh M, Lee P, Fanelli R, Loperfido F, Berman JW, LeJemtel TH. Circulating levels of cytokines and their endogenous modulators in patients with mild to severe congestive heart failure due to coronary artery disease or hypertension. J Am Coll Cardiol 1996; 28: 964-971.

21 Torre-Amione G, Kapadia S, Benedict C, Oral H, Young JB, Mann DL. Proinflammatory cytokine levels in patients with depressed left ventricular ejection fraction a report from the Studies of Left Ventricular Dysfunction (SOLVD). J Am Coll 1996; 27: 1201-1206.

22 Damås JK, Gullestad L, Aass H, Simonsen S, Fjeld J, Wikeby L, Ueland T, Eiken HG, Frøland SS, Aukrust P. Enhanced gene expression of chemokines and their corresponding receptors in mononuclear blood cells in chronic heart failure modulatory effects of intravenous immunoglobulin. J Am Coll Cardiol 2001; 38: 187-193.

23 Ono K, Matsumori A, Shioi T, Furukawa Y, Sasayama S. Cytokine gene expression after myocardial infarction in rat hearts: possible implication in left ventricular remodeling. Circulation 1998; 98: 149-156.

24 Deveaux B, Scholz D, Hirche A, Kløverkorn WP, Schaper J. Upregulation of cell adhesion molecules and the presence of low grade inflammation in human chronic heart failure. Eur Heart J 1997; 18: 470-479.

25 Damås JK, Eiken HG, Øie E, Bjerkeli V, Yndestad A, Ueland T, Tonnessen T, Geiran OR, Aass H, Simonsen S, Christensen G, Froland SS, Attramadal H, Gullestad L, Aukrust P. Myocardial expression of CC- and CXC-chemokines and their receptors in human end-stage heart failure. Cardiovasc Res 2000; 47: 778-787.

26 Deswal A, Petersen NJ, Feldman AM, Young JB, White BG, Mann DL. Cytokines and cytokine receptors in advanced heart failure: an analysis of the cytokine database from the Vesnarinone Trial (VEST). Circulation 2001; 103: 2055-2059.

27 Mann DL. Inflammatory mediators and the failing heart: past, present, and the foreseeable future. Circ Res 2002; 91: 988-998.

28 Deswal A, Misra A, Bozkurt B. The role of anti-cytokine therapy in the failing heart. Heart Fail Rev 2001; 6: 143-151.

29 Oudit GY, Kassiri Z, Patel MP, Chappell M, Butany J, Backx PH, Tsushima RG, Scholey JW, Khokha R, Penninger JM. Angiotensin II-mediated oxidative stress and inflamma- tion mediate the age-dependent cardiomyopathy in ACE2 null mice. Cardiovasc Res 2007; 75: 29-39.

30 Keidar S, Kaplan M, Gamliel-Lazarovich A. ACE2 of the heart: from angiotensin I to angiotensin (1-7). Cardiovasc Res 2007; 73: 463-469.

31 Toyokuni S, Tanaka T, Hattori Y, Nishiyama Y, Yoshida A, Uchida K, Hiai H, Ochi H, Osawa T. Quantitative immunohistochemical determination of 8-hydroxy- 2-deoxyguanosine by a monoclonal antibody N45.1: its application to ferric nitrilotriacetateinduced renal carcinogenesis model. Lab Invest 1997; 76: 365-374.

32 Kinugawa S, Tsutsui H, Hayashidani S, Ide T, Suematsu N, Satoh S, Utsumi H, Takeshita A. Treatment with dimethylthiourea prevents left ventricular remodeling and failure after experimental myocardial infarction in mice: role of oxidative stress. Circ Res 2000; 87: 392-398.

33 Suematsu N, Tsutsui $H$, Wen J, Kang D, Ikeuchi M, Ide T, Hayashidani S, Shiomi T, Kubota T, Hamasaki N, Takeshita A. Oxidative stress mediated tumor necrosis factor $\alpha$-induced mitochondrial DNA damage and dysfunction in cardiac myocytes. Circulation 2003; 107: 1418-1423.

34 Meldrum DR, Dinarello CA, Shames BD, Cleveland Jr JC, Cain BS, - , Meng X, Harken $\mathrm{AH}$. Hydrogen peroxide induces tumor necrosis factor $\alpha$-mediated cardiac injury by a p38 mitogen activated protein kinase dependent mechanisms. Surgery 1998; 124: 291-296.

35 Nakamura K, Fushimi K, Kouchi H, Mihara K, Miyazaki M, Ohe T, Namba M. Inhibitory effects of antioxidants on neonatal rat cardiac myocyte hypertrophy induced by tumor necrosis factor- $\alpha$ and angiotensin II. Circulation 1998; 98: 794-799.

36 Liao XX, Guo RX, Ma H, Wang LC, Chen ZH, Yang CT, Feng JQ. Effects of angiotensin$(1-7)$ on oxidative stress and functional changes of isolated rat hearts induced by ischemia-reperfusion. Nan Fang Yi Ke Da Xue Xue Bao 2008; 28: 1345-1348. Chinese.

37 Ueda H, Nakamura T, Matsumoto K, Sawa Y, Matsuda H, Nakamura T. A potential cardioprotective role of hepatocyte growth factor in myocardial infarction in rats. Cardiovasc Res 2001; 51: 41-50.

38 Santos RA, Castro $\mathrm{CH}$, Gava E, Pinheiro SV Almeida AP, de Paula RD, Cruz JS, Ramos AS, Rosa KT, Irigoyen MC, Bader M, Alenina N, Kitten GT, Ferreira AJ. Impairment of in vitro and in vivo heart function in angiotensin-(1-7) receptor Mas knockout mice. Hypertension 2006; 47: 996-1002.

39 Giani JF, Gironacci MM, Muñoz MC, Turyn D, Dominici FP. Angiotensin-(1-7) has a dual role on growth-promoting signalling pathways in rat heart in vivo by stimulating STAT3 and STAT5a/b phosphorylation and inhibiting angiotensin II-stimulated ERK1/2 and Rho kinase activity. Exp Physiol 2008; 93: 570-578.

40 Su Z, Zimpelmann J, Burns KD. Angiotensin-(1-7) inhibits angiotensin II-stimulated phosphorylation of MAP kinases in proximal tubular cells. Kidney Int 2006; 69: 2212-2218.

41 Sampaio WO, Souza dos Santos RA, Faria-Silva R, da Mata Machado LT, Schiffrin EL, Touyz RM. Angiotensin-(1-7) through receptor mas mediates endothelial nitric oxide synthase activation via Akt-dependent pathways. Hypertension 2007; 49: 185-192.

42 Tallant EA, Ferrario CM, Gallagher PE. Angiotensin-(1-7) inhibits growth of cardiac myocytes through activation of the mas receptor. Am J Physiol Heart Circ Physiol 2005; 289: H1560-H1566. 